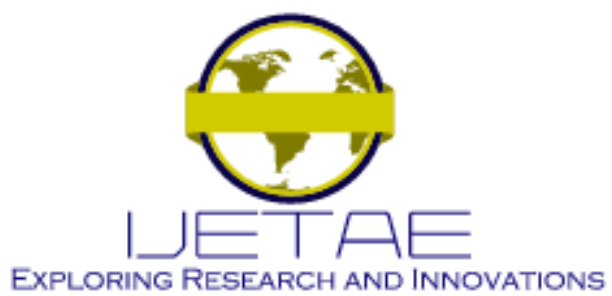

International Journal of Emerging Technology and Advanced Engineering

Website: www.ijetae.com (E-ISSN 2250-2459, Scopus Indexed, ISO 9001:2008 Certified Journal, Volume 12, Issue 01, January 2022)

Manuscript Received: 02 December 2021, Received in Revised form: 04 January 2022, Accepted: 12 January 2022

DOI: $10.46338 /$ ijetae0122_16

\title{
Cloud Computing Models for Business
}

\author{
Irina Alekseevna Vorobeva ${ }^{1}$, Alexander Vladimirovich Panov ${ }^{2}$, Alexander Arkadyevich Safronov ${ }^{3}$, \\ Alexey Ivanovich Sazonov ${ }^{4}$ \\ 1,2,3,4 MIREA—Russian Technological University, 78 Vernadsky Prospect, Moscow, 119454, Russia
}

\begin{abstract}
The idea of cloud computing is not a new one, it has been developed and discussed for many years. Cloud computing is a model which allows to get access to the network upon request from the set of adjustable computing services, such as infrastructure, applications and storages. Cloud services and data storage products allow their users to store and share any type of document and file from any device connected to Internet. There are several types of cloud services, which can be subdivided into: SaaS (Software as a Service), PaaS (Platform as a Service), IaaS (Infrastructure as a Service). Besides, there are several deployment models, such as public, residential, hybrid or community cloud. Cloud computing models are based on modern process paradigm, which offers new alternatives to the companies of various ranges for implementation of innovative business models. With the help of these new business models small companies will be able to use cloud computing platforms and to increase gradually their computation capacities and data storage capacities depending on the requirements in real time mode, which creates a unique opportunity for market competition.
\end{abstract} SaaS.

Keywords - cloud computing, IaaS, OpenStack, PaaS,

\section{INTRODUCTION}

Process infrastructure, especially related to information and communication technologies, has become necessary for any enterprise, irrespective of a sector it belongs to. One of terms which gains more and more importance due to the constant evolution in such technological aspects as transferability, mobility and convergence of both hardware and software is definitely cloud computing [1].

Today cloud computing is one of the most frequently used technologies due to increase of its flexibility and scalability for services and applications. Cloud computing is a model which allows to secure access upon request to the set of adjustable computing resources (such as networks, servers, application and service storages), which can be quickly provided and available to a customer with minimum efforts on control and interaction with service provider. This allows to use large-scale innovative methods for access to geographically distributed resources.
One of main advantages of cloud computing is that information and resources are available at any time in any place of the world which has Internet connection. Besides, from economic expenditures point of view, cloud computing is cheaper than other computing models [2].

Cloud technologies are viewed as change of paradigm, because the users do not need any more to professionalize in computer hardware which they use for everyday business activities or fulfilling such routine tasks as storage of a large number of electronic letters or communication in a social network with people all over the world [3].

As per NIST (National Institute of Standards and Technology) definition, which is one of the most widely acknowledged, the cloud computing consists of five main characteristics, three maintenance models and four deployment models [4].

\section{Main Features Of Cloud COMPUting}

- Self-service upon request: the customer can unilaterally provide himself server time and network storage whenever required without communication with service provider [5].

- Cost: low barrier of entry, because it is not required to purchase infrastructure for one-time computing tasks, because it is provided by the third party.

- Scalability and flexibility: cloud systems automatically control and optimize used resources with the help of possibility of change at abstraction level, corresponding to the type of provided service (storage, processing, throughput, etc.) [6].

- Efficiency: cloud systems automatically control and optimize resources usage.

- Independence between the device and its location: it allows users to get access to the systems with the help of web browser, irrespective of their location or used device. Virtualization technology allows to share servers and data storage devices. Applications can be easily transferred from one physical server to other. 


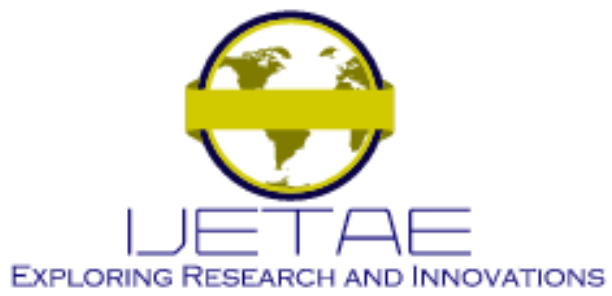

International Journal of Emerging Technology and Advanced Engineering

Website: www.ijetae.com (E-ISSN 2250-2459, Scopus Indexed, ISO 9001:2008 Certified Journal, Volume 12, Issue 01, January 2022)

\section{Models Of Cloud InFRASTRUCTURE MAINTENANCE}

There is a hierarchy of services which can be offered in a cloud, depending on degree of abstraction and outsourcing, required by user's facility [7]. Cloud computing model comprises a three-level architecture: Software as a Service (SaaS), Platform as a Service (PaaS) и Infrastructure as a Service (IaaS) [8]. These models are usually called "SPI model" [9].

\section{A. Saas}

Software as a Service is the upper level of service which is in charge of web services deployment and their provision to end users, it is achieved due to implementation of multitenancy. The customer does not control the basic cloud infrastructure, which involves the network, servers, operational systems, storages or possibility of individual applications, except limited parameters of application configuration for a definite user.

A typical example of SaaS is Gmail, Google e-mail program. Gmail is nothing more than the program used in a browser, it secures the same capability as Microsoft Outlook or Apple Mail, but without mail account adjustment [10-11].

\section{B. Paas}

Platform as a Service belongs to the middle level of cloud service. PaaS are software platforms for which the development tool itself is located in a cloud and available via web browser. With PaaS the developers can design, test and deploy web applications without installation of additional tools on their computers or having any special administrative knowledge. These platforms can service all stages of software development and testing cycle or can be designated for a special area, such as content administration [12]. One of examples is Google Apps Engine, which allows to develop, share and locate external web applications in its broad infrastructure.

This model allows to eliminate expenses and difficulties related to purchasing and administration of software licenses, basic infrastructure of applications, intermediate software and other resources. One of its peculiarities is that the client administrates applications and services which he develops, and service provider administrates all the rest: security, operational systems, server software and backup copies, being also in charge of resources scaling for optimal performance of the platform, etc.
Though this model has many advantages for clients, it also has some disadvantages. PaaS service offers usually have some proprietary elements, such as development tools or component libraries. Therefore, the client can be bound to supplier's platform and will not be able to transfer his applications to other places without necessity to rewrite the code.

\section{Iaas}

Infrastructure as a Service is a lower level of the cloud service. In this service model the service provider provides its users the infrastructure in the form of a disk space, database systems, load balancers, routers, commutators and other main computing resources, on which the consumer can deploy and launch unrestricted software, such as operational systems or applications. Physically the repertoire of available software resources comes from many servers and networks, which are usually distributed between numerous centers of data processing, their maintenance is the scope of the cloud services provider [13]. The user does not administrate and does not control the basic cloud infrastructure (hypervisor, equipment and network), instead he gets an access to visualized components to create his own computing platform [14].

IaaS advantage is that it can secure automatic or semiautomatic scalability, so that it could be possible to hire more resources in compliance with the requirements.

\section{MODEls Of ClOUd INFRASTRUCTURE DEPLOYMENT}

The optimal model of cloud deployment depends on the applications nature, working load and type of data stored in a cloud. While selecting the means of safety and confidentiality control it is important to understand the necessities of each company at operation in a cloud and to distinguish the models of services provision clearly. However, irrespective of the used service model (SaaS, $\mathrm{PaaS}$, IaaS) there are four main ways of cloud services deployment: residential, public, hybrid or community [15].

\section{A. Private Cloud}

As a rule, residential cloud is a platform only for hardware receiving, i.e. machines, storages and network infrastructure (IaaS), but it can also be used for deployment of platforms (PaaS) and even software (SaaS). Advantage of this type of infrastructure is data localization within the company, it allows to store information in a maximum confidential way, meeting the regulatory requirements. 


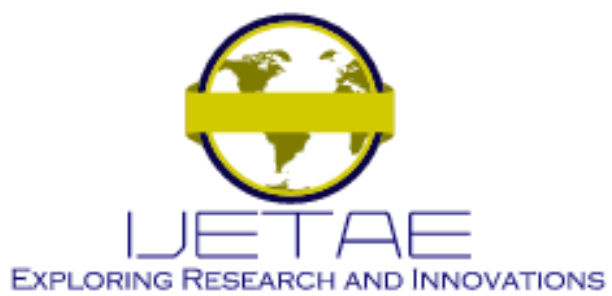

International Journal of Emerging Technology and Advanced Engineering Website: www.ijetae.com (E-ISSN 2250-2459, Scopus Indexed, ISO 9001:2008 Certified Journal, Volume 12, Issue 01, January 2022)

Residential clouds are a good choice for companies which need high protection of data. However, there are disadvantages, such as: high expenses (they require the same human, administrative, operating and capital resources as conventional data processing centers, as well as virtualization systems, special software and control tools), dependence on a certain infrastructure and limit of computing resources capacity.

\section{B. Public Cloud}

Within this deployment model several clients have an access to infrastructure, software and development platforms, so their data and information will be stored together with other users' data. The advantages are scalability, efficiency of resources usage and economy of time and expenses on technical maintenance. Public cloud safety is lower, because processes of several clients are mixed on servers, in storage systems and other cloud infrastructures. Applications, storages and other resources are available via service provider, which owns the whole infrastructure in its data processing centers.

\section{Community Cloud}

With the help of this type of cloud various companies which have the same targets and objectives can share their computing and process resources. Some of advantages can be in its adaptation to observation of the company internal policy of safety and confidentiality, reduction of expenses as a result of a joint usage of infrastructure and resources, as well as quicker return on investment, as opposed to residential ones. There are less users in this deployment model than in the public cloud, that's why it secures a higher level of confidentiality and safety. However, safety also depends on infrastructure location, which can be either at the territory of the company or outside.

\section{Hybrid Cloud}

This model is a combination of two or more clouds (residential, public or community), which are supported as individual objects but are joint by proprietary or their own technologies.
This scheme secures reduction of expenses compared to a residential cloud model and allows to have integrated standards with data and applications transferability for load balancing between them. For example, storage of confidential information in a residential cloud connected to a shared cloud for scalability and peak demands. Hybrid clouds offer scaling contemplations, but add difficulty to determination how to distribute applications in these different environments. One of examples of this model is enterprise e-mail systems.

\section{Cloud Architecture}

Architecture of cloud computing is similar to a network one and consists of a number of layers linked with each other to secure the system functionality. The reason is that cloud computing use protocols identical to those on which TCP/IP model is based.

General architecture of cloud computing has the following levels, mentioned from the bottom upwards:

- Physical resources: comprise such elements as servers, storages and network.

- Virtualization: comprises virtual infrastructure as a service [8].

- Infrastructure: comprises platform software as a service.

- Platform: comprises components of application as a service.

- Implementation: comprises web services and software as a service.

\section{VIRTUALIZATION}

Virtualization simplifies creation of dynamically scaled architectures and gives possibility to transfer virtual machines for load balancing, which allows to launch different operational systems on one physical computer (Figure 1). 


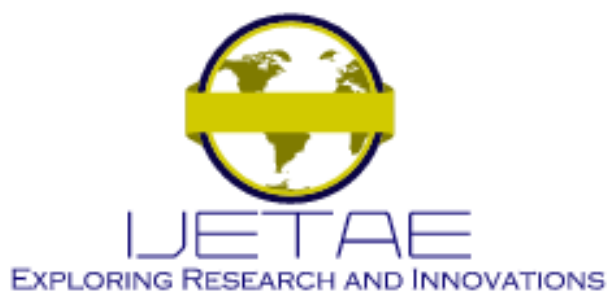

International Journal of Emerging Technology and Advanced Engineering

Website: www.ijetae.com (E-ISSN 2250-2459, Scopus Indexed, ISO 9001:2008 Certified Journal, Volume 12, Issue 01, January 2022)

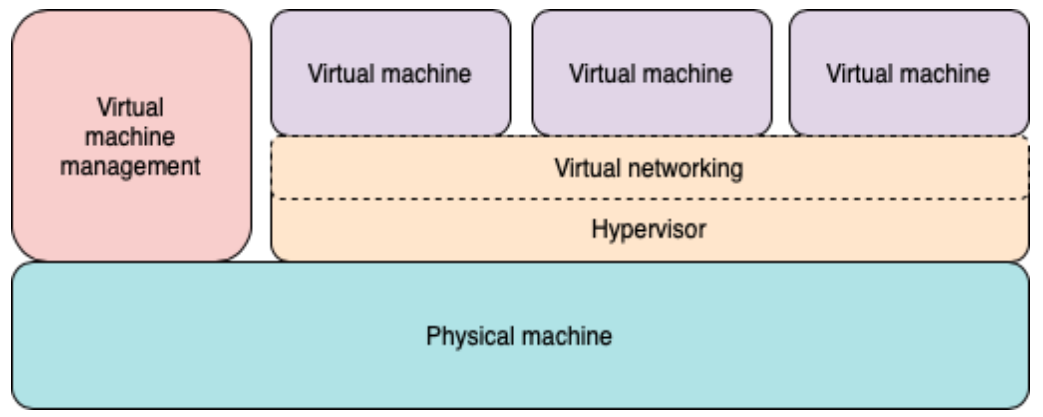

Figure 1. Virtualization Architecture

Software for virtual machines control is a hypervisor which is operating at the level of nodes in a cloud. Besides, it provides joint usage of resources of physical computer, such as processor, memory and hard disk (storage), which allows to achieve resources efficiency, saving energy and optimizing the occupancy of a physical area of data processing center.

The hypervisor has an element called virtual machine (VM), which encapsulates the operational system, applications and configuration. If required, the device emulation can be provided in hypervisor or as a virtual machine.

\section{A. Xen}

Xen is a hypervisor with an open source, which allows to consolidate and to launch simultaneously several images of operational systems on one physical server. Xen is the quickest and most safe infrastructure of program virtualization, which has been approved by big manufacturers, including Intel, AMD, Dell, HewlettPackard, IBM and so on.

Virtual server is a specimen of operational system ans its operating load, working under the aegis of hypervisor. Instead of direct control of equipment, specimens of operational systems get access to the equipment via hypervisor, which also can share the resources with other applications and specimens of virtualized operational systems.

Virtual machines Xen can be transferred between physical hosts without necessity to stop them. During this process the virtual machine memory is iteratively copied to the point of destination without interruption. A small pause between 60 and 300 milliseconds is required for final synchronization before the virtual machine starts operation at its new place.

\section{B. $K V M$}

In a typical scenario of virtualization the hypervisor secures interface between the guest system and its host. The hypervisor is located in the top section of a host system, it is in charge of the tasks planning and memory control for each guest. KVM integrates the hypervisor into the core, thereby reducing the redundancy and accelerating the runtime.

KVM driver interacts with the core, serving as an interface for a virtual machine in the user space. Tasks planning and memory control are processed by the same core. A small module of the core Linux represents the guest mode, installs page tables for it and emulates certain key instructions.

Current versions of KVM are supplied with modified version of qemu emulator, which controls input-output and operates as a virtual residence for a guest system. Guest system operates inside qemu, and qemu - in the user space.

KVM module activates the guest mode and controls virtualized access to records. From user's point of view, there is hardly any difference between starting the virtual machine qemu with disabled KVM and its starting with activated KVM, except, of course, a considerable increase of speed.

\section{C. $E S X i$}

Hardware hypervisor from VMware company, the main particularity of which is its installation directly on a physical server. It is equipped with centralized graphical console and administration monitoring. This allows to get a complete control over VM and access to such interaction functions as reloading, ISO assembling and so on. Hypervisor has a high-quality system of uninterrupted migration, which allows to transfer VM to other place and deploy it there practically without delay. 


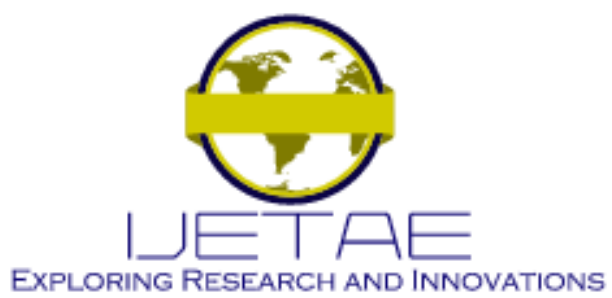

International Journal of Emerging Technology and Advanced Engineering

Website: www.ijetae.com (E-ISSN 2250-2459, Scopus Indexed, ISO 9001:2008 Certified Journal, Volume 12, Issue 01, January 2022)

\section{Cloud Prototype Based On Openstack}

There are various solutions for deployment of clouds with open source, among them the most famous are OpenNebula, Eucalyptus and OpenStack. [16]

OpenStack is a cloud computing platform which is most widely used at present. It supports residential and public clouds and leaves an option of manual adjustment which is easily programmed due to API variety. OpenStack supports various operational systems and hypervisors, such as: ESX, Hyper-V, KVM, LXC, QEMU, UML, Xen and XenServer and has 3-node cloud structure: computing, storage and network.

OpenStack platform is provided for massive infrastructures. It allows to deploy infrastructure as a service via several services, which are coordinated and have different objectives. Depending on user's necessities some or all available services can be installed [17-18].

\section{A. OpenStack Compute (Nova)}

This software is in charge of starting specimens (virtual machines) and their life cycle. Nova is a control platform for computing resources, networks, authorization and scalability requirements for OpenStack cloud.

But Nova by itself does not provide any virtualization opportunities, instead it uses API libvirt for interactions with compatible hypervisors.

Components of nova: DB, control web-panel, API, authentication catalogue, objects storage, timetable, network and computing. Hypervisors of each virtual machine server are processed in the same way.

\section{B. OpenStack Identity Service (Keystone)}

Keystone provides authentication services for a cloud, it is in charge of users, roles and projects control. It provides the catalogue of all OpenStack services, using authentication system based on tokens. Each Keystone function has got a backend, which allows to use services in different ways.

\section{OpenStack Image Service (Glance)}

Glance controls system image templets and specimens' photos. It provides services of search, registration and restoration of virtual disks images, has RESTFul API, which allows to prompt for metadata of images. Most formats of images storage are supported, for example [19]: raw, qcow2 (Qemu / KVM), vhd (Hyper-V), ami (Amazon), vdi (VirtualBox), vmdk (VMware).
Glance has got daemons in charge of virtual machines creation, namely: Glance-api (receives users' requests for machines creation) and Glance-registry: (in charge of virtual machines metadata storage).

\section{OpenStack Dashboard (Horizon)}

Horizon is a web-panel of OpenStack tools, which provides graphic interface to administrators and users for access and automatization of cloud services, considering predefined policies. Clients' access is performed via webinterface, via HTTP protocol. Horizon performs such operations as specimens control and startup, networks creation and correlation, and first of all, users' authentication.

Besides, the interface allows users to interact with other OpenStack tools, such as monitoring. Expandable structure allows to connect external products and services easily, as a result the developers can automate access or design tools for their resources administration with the help of their own API OpenStack or API compatibility EC2.

\section{E. OpenStack Block Storage (Cinder)}

Cinder provides constant storage at the level of blocks called volumes, to be used with virtual machines. Volumes are created as LVM (logical volume manager) on storage node and are connected to the specimen with the help of the storage network protocol, such as iSCSI, which is most widely used. Volumes are considered to be external disks which are connected to the specimens or disconnected from them.

Besides using storage, Cinder provides integrated support of numerous communication platforms, including Ceph, NetApp, Nexenta, SolidFire and Zadara. This service provides control functions for data backup copies, saved in blocks, which can be restored or used for creation of new storage volumes. As disadvantage one can single out impossibility to link the volume with more than one specimen. Cinder comprises Cinder-api, Cinder-volume, Cinder-scheduler and waiting list for messages exchange.

\section{F. OpenStack Networking (Neutron)}

Network administration service - it controls the physical network of machines, allowing users to create networks and connect specimens to each other. Neutron secures network and IP-address administration, including users' network models for various applications or users' profiles. 


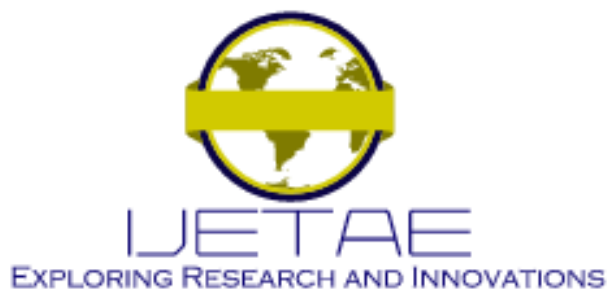

International Journal of Emerging Technology and Advanced Engineering

Website: www.ijetae.com (E-ISSN 2250-2459, Scopus Indexed, ISO 9001:2008 Certified Journal, Volume 12, Issue 01, January 2022)

Secures access to Internet for virtual machines with the help of shared or private IP-addresses, which can be allotted dynamically or statically. Users can create their own virtual networks, comprising several virtual machines which operate in different local networks. The other feature of Neutron is virtualization of IP-addresses space, which allows different users to use the same IP-addresses repeatedly for their virtual machines. Besides, Neutron is integrated with Horizon and provides possibility to adjust the network via graphic interface.

\section{IMPLEMENTATION}

OpenStack supports installation on Linux-distributives Ubuntu, RedHat, CentOS, openSUSE and SUSE. It does not mean that it cannot be installed on other systems, but for these distributives detailed installation instructions are provided.

A prototype of residential cloud was deployed based on OpenStack of Infrastructure-as-Service type on CentOS 7 distributive for testing as a redundant cloud solution and testing of horizontal and vertical scaling.

There are several ways of OpenStack installation in CentOS: manual and automatic installation. Automatic installation takes place, for example, with the help of kollaansible and significantly simplifies the process of OpenStack deploy, because it requires only initial adjustment of virtual machines (which can be also simplified and accelerated with the help of playbook or bash-scripts) and several configuration files, and installation of the system itself takes place with the help of configurations control mechanism - ansible. Manual installation suggests changing of a large number of configuration files directly on each node.

Kolla-ansible has two variants of system deployment: multinode and all-in-one. Variant selection depends on objectives, tasks and available equipment. The first variant is used at the availability of several computing nodes, the second variant is for installation of all system components on one node. In this work it is expected to use a three-node architecture, comprising a controller and two computing nodes.

To deploy the proposed architecture of OpenStack platform, two network interfaces shall be installed on each node. Interface eth0 for connection between nodes and eth1 for external network traffic. In configuration files it is necessary to adjust a dynamic allotment of IP address and interface switching on at the system loading. Besides, date and time shall be synchronized on all the nodes. Further on repositories are added and all required packets are installed as per instruction. Then configuration files are adjusted and deployment is performed.

As a result of the work performed we have obtained a completely functional cloud infrastructure of IaaS type based on OpenStack (Figure 2). 


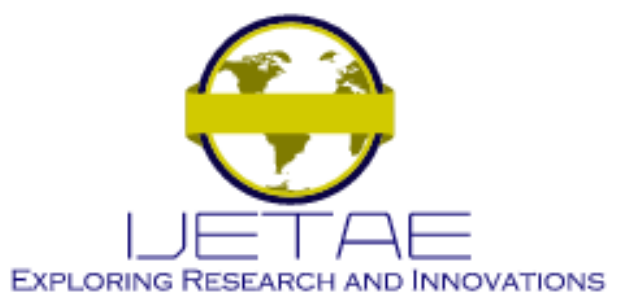

International Journal of Emerging Technology and Advanced Engineering

Website: www.ijetae.com (E-ISSN 2250-2459, Scopus Indexed, ISO 9001:2008 Certified Journal, Volume 12, Issue 01, January 2022)

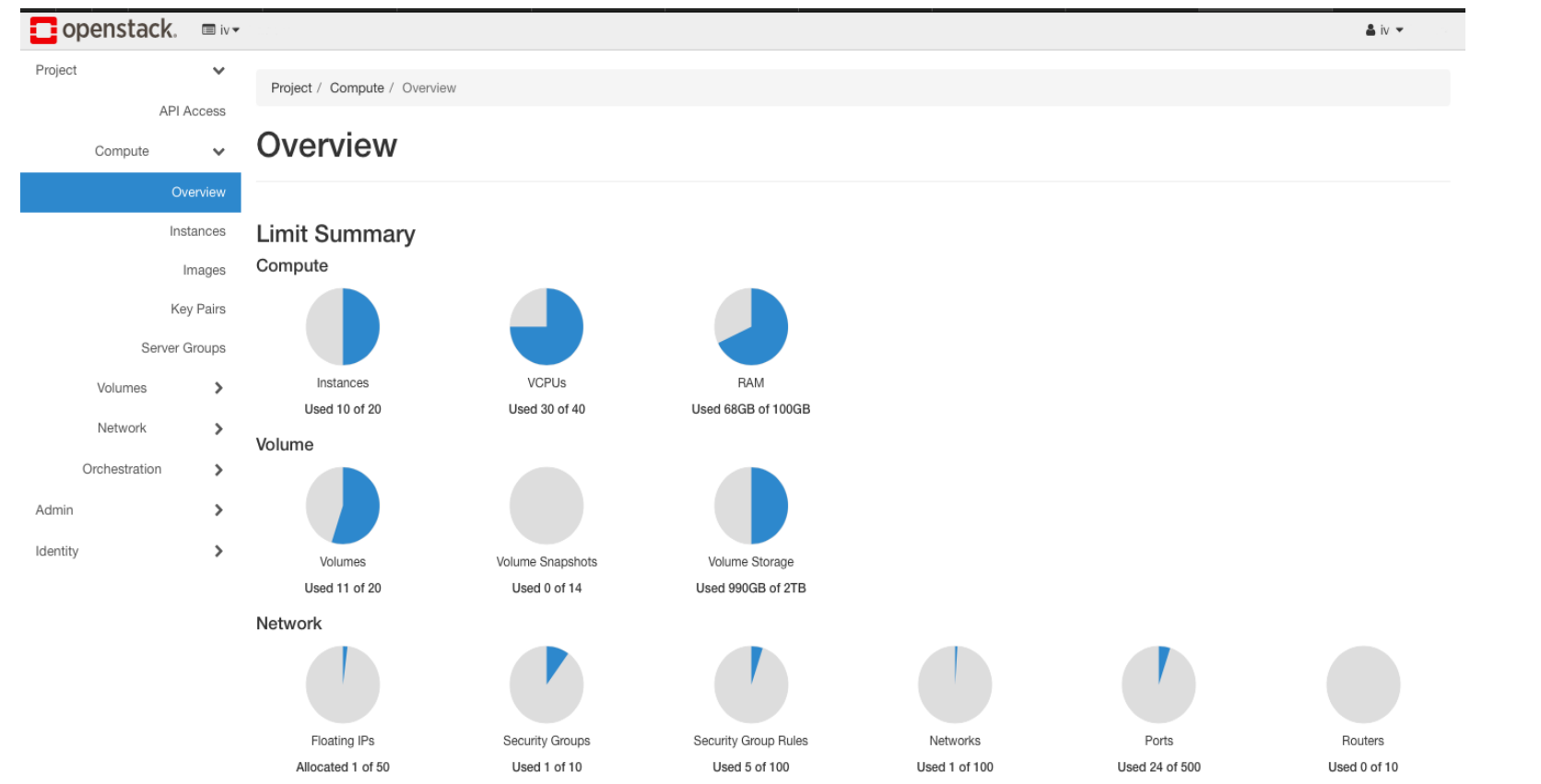

Figure 2. Overview of Computing Resources via Dashboard

When the system is installed and launched, let us compare the efficiency which is offered by virtualized system compared to original equipment. We'll perform a series of efficiency tests for main components: processor, DDR memory, network and disk.
The first one is CPU test, measuring efficiency of host and specimen processor with the help of OpenSSL (Figure 3).

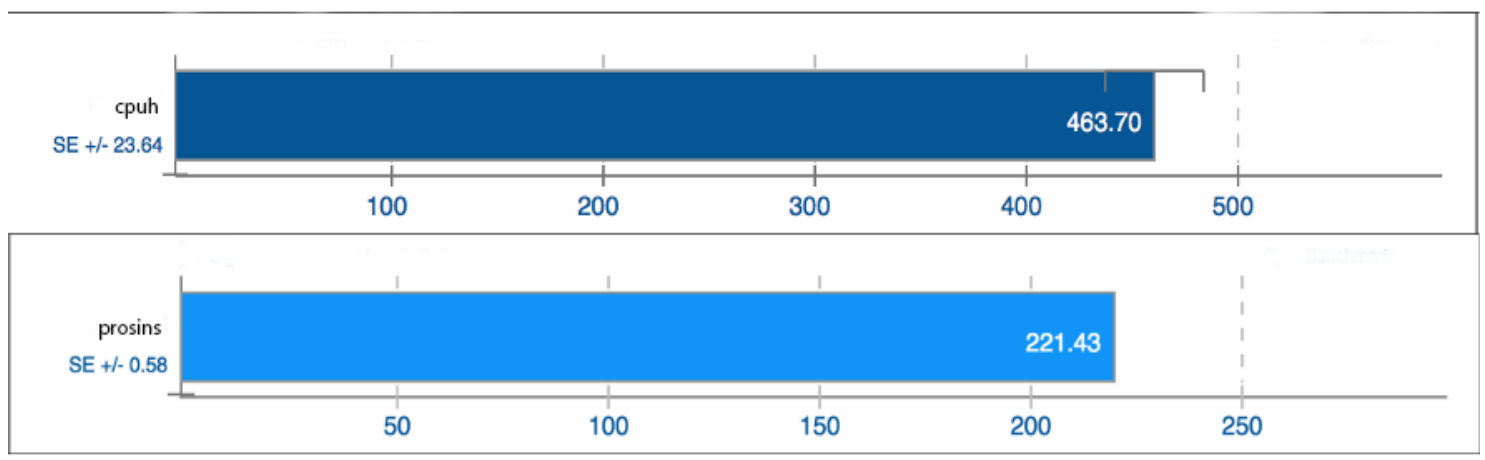

Figure 3. CPU Test

As a result, the computer efficiency without virtualization is almost two times bigger compared to the specimen. The reason is that the created machine has only two cores, and the host has four, that's why it makes allowance for a half of efficiency.
System memory efficiency test consisted of reading, record and scaling (Figure 4). 


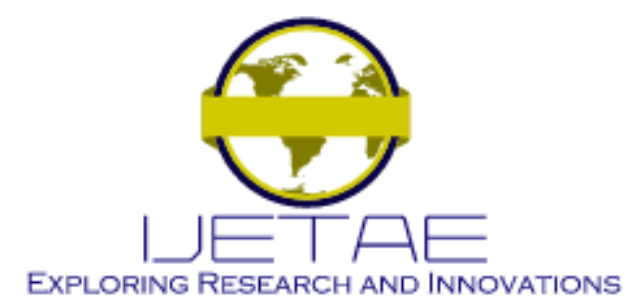

International Journal of Emerging Technology and Advanced Engineering

Website: www.ijetae.com (E-ISSN 2250-2459, Scopus Indexed, ISO 9001:2008 Certified Journal, Volume 12, Issue 01, January 2022)

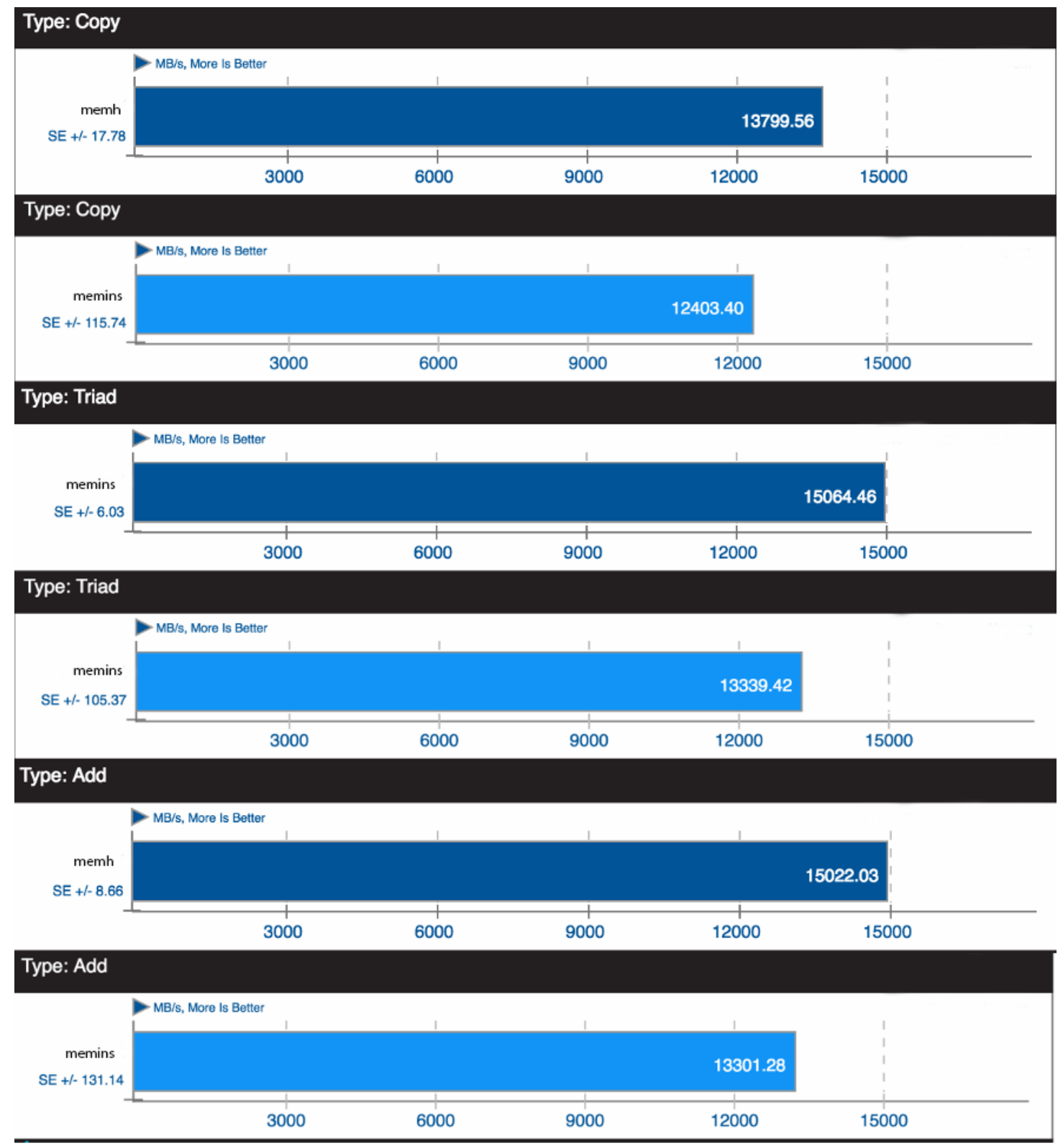

Figure 4. Efficiency Test

The results difference is not as big as in previous test.

Disk efficiency test included reading (Figure 5) and record (Figure 6). 


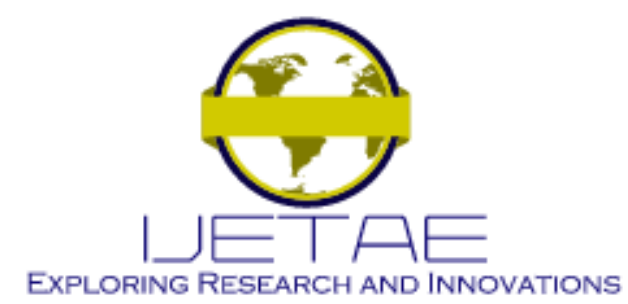

International Journal of Emerging Technology and Advanced Engineering

Website: www.ijetae.com (E-ISSN 2250-2459, Scopus Indexed, ISO 9001:2008 Certified Journal, Volume 12, Issue 01, January 2022)

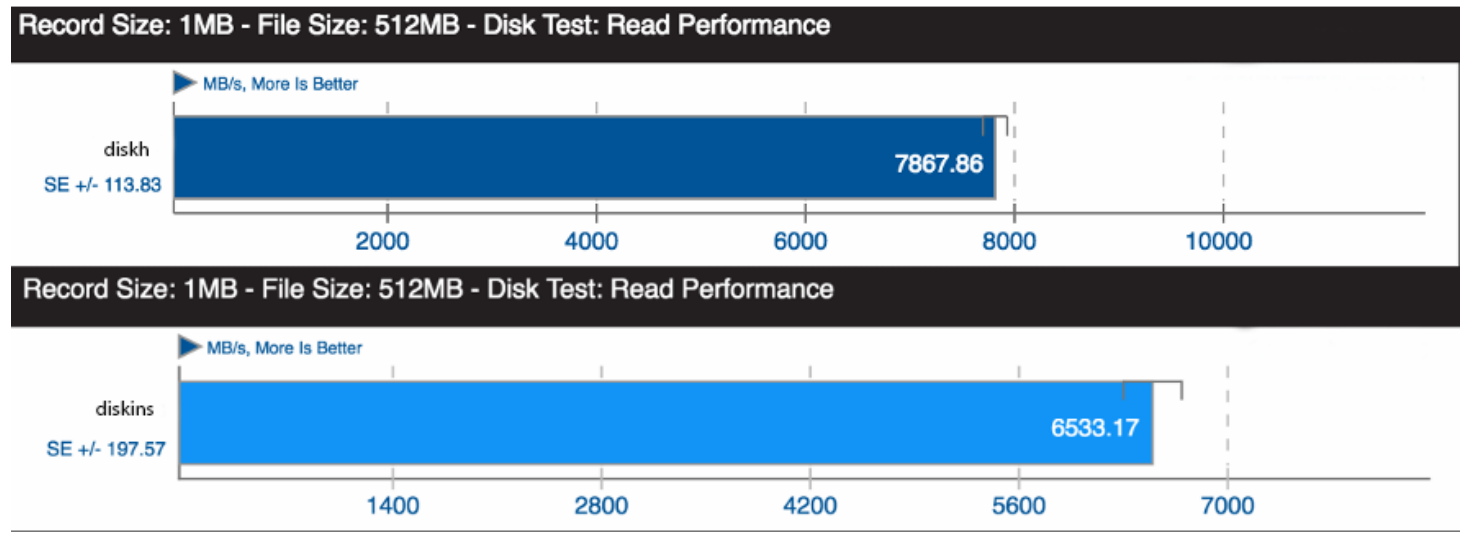

Figure 5. Reading Test

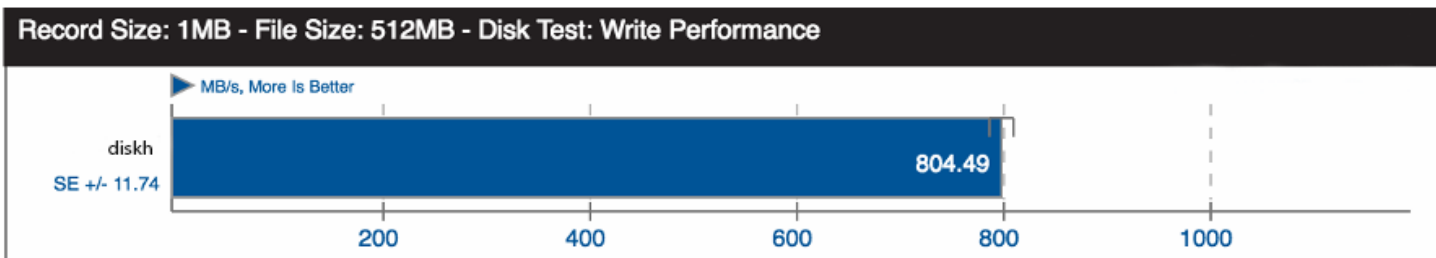

Record Size: 1MB - File Size: 512MB - Disk Test: Write Performance

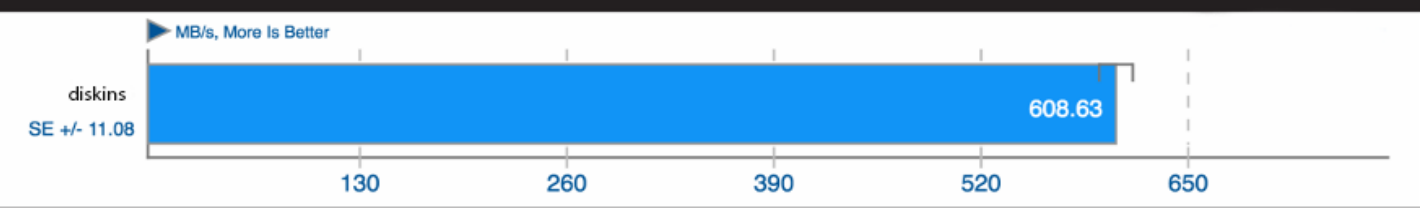

Figure 6. Record Test

As in case of memory, the difference is not as big as at processor work measurement.
Network tests concluded in 10 GB file transfer (Figure 7).

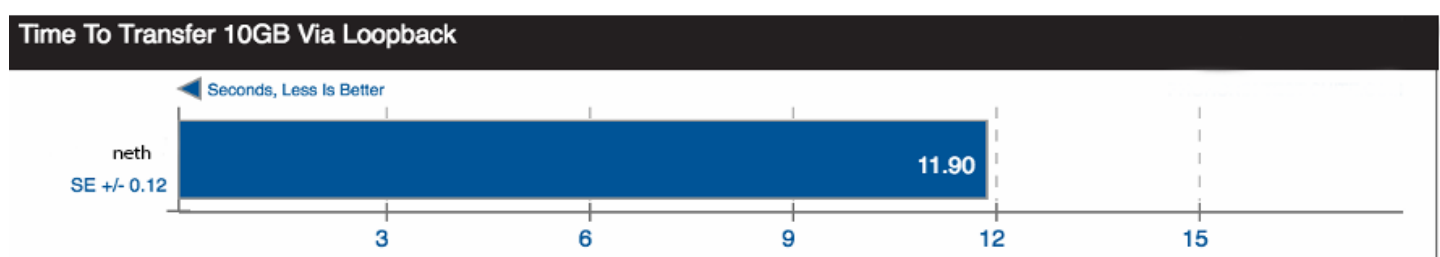

Time To Transfer 10GB Via Loopback

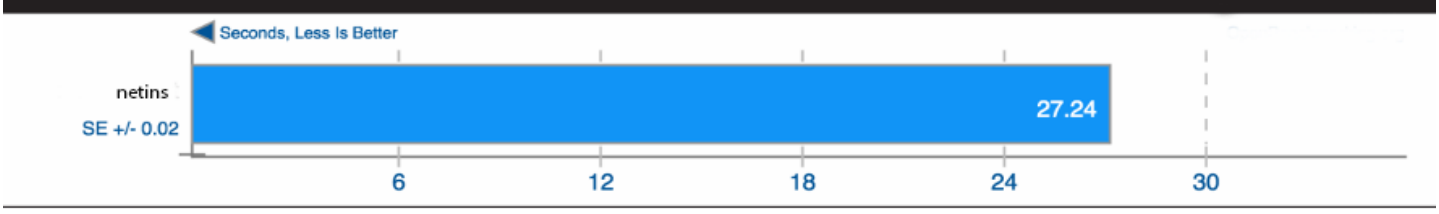

Figure 7. Network Tests 


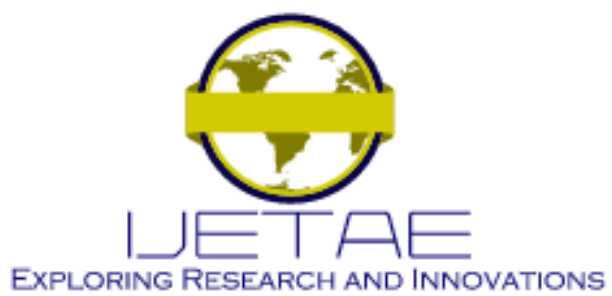

International Journal of Emerging Technology and Advanced Engineering Website: www.ijetae.com (E-ISSN 2250-2459, Scopus Indexed, ISO 9001:2008 Certified Journal, Volume 12, Issue 01, January 2022)

The specimen had much lower efficiency than the host, demanding almost three times more time for performing the same operation. The reason is that the test was performed on virtual interface, on which the host-system performs all operations which physical network card would perform.

Analyzing the results obtained, we may say that instantiated specimens secure optimal efficiency but considerably overload the components efficiency compared to the main computer.

\section{CONCLUSION}

In the course of work the subject field has been analyzed, cloud computing and virtualization have been reviewed, as well as service models and cloud infrastructure deployment. OpenStack stand had been deployed with three-node architecture and key components had been tested. After deployment and analysis of each test results the conclusion was made that OpenStack is a stable system which demonstrates high availability, redundancy, horizontal and vertical scaling

As a conclusion we may say that cloud technologies is a dramatically developing field with high opportunities. They secure individual users' access to information, entertainment, application and service resources in a more flexible, quick and cost efficient way, and give enterprises new opportunities to schematize their processes in a more efficient way, reducing initial investments into equipment and software.

\section{REFERENCES}

[1] I.A. Mandych, and A.V. Bykova, "Difficulties and opportunities of development hi-technology projects in the age of digital transformation of economy", Russian Technological Journal, vol. 9, no. 2, pp. 88-95, 2021.

[2] I. Lee, "Pricing and profit management models for SaaS providers and IaaS providers", Journal of Theoretical and Applied Electronic Commerce Research, vol. 16, no. 4, pp. 859-873, 2021.

[3] K. Shishmanov, "Peculiarities of information systems development at small enterprises", Russian Technological Journal, vol. 4, no. 5, pp. 63-69, 2016.

[4] E. Simmon, Evaluation of cloud computing services based on NIST SP 800-145. Special Publication (NIST SP). Gaithersburg, MD: National Institute of Standards and Technology, 2018. https://doi.org/10.6028/NIST.SP.500-322
[5] OECD, Cloud computing: The concept, impacts and the role of government policy. OECD Digital Economy Papers no. 240. Paris, France: OECD Publishing, 2014.

[6] E. Gorelik, "Cloud computing models", submitted for the Degrees of Master of Management and Master of Engineering in conjunction with the System design and management program, Massachusetts Institute of Technology, Cambridge, MA, 2013, $81 \mathrm{p}$.

[7] R. Buyya, C.S. Yeo, S. Venugopal, J. Broberg, and I. Brandic, "Cloud computing and emerging IT platforms: Vision, hype, and reality for delivering computing as the 5th utility", Future Gener, vol. 25 , no. 6, pp. 599-616, 2009 .

[8] U. Divakarla, and K. Geetha, "An overview of cloud computing in distributed systems", AIP Conference Proceedings, no. 1324, pp. 184-186, 2010.

[9] K. Preetpal, "A simplified approach of SPI service model in cloud computing", International Journal of Innovative Computer Science \& Engineering, vol. 4, no. 5, pp. 1-9, 2017.

[10] S. Sidra, "Cloud computing: Issues regarding technology and proposed solutions", Student Research Paper Conference, vol. 2, no. 9, pp. 45-50, 2015.

[11] S. Satyanarayana, "Cloud computing: SAAS", GESJ: Computer Science and Telecommunications, vol. 4, no. 36, pp. 76-79, 2012.

[12] J.T. Flores Callejas, and P. Dumitriu, Managing cloud computing services in the United Nations system. Report of the Joint Inspection Unit. United Nations, Geneva, 2019, 76 p.

[13] V.A. Tretyakov, G.V. Kulikov, and Yu.F. Lukyanets, "Principles of development of big geographically distributed automated systems", Russian Technological Journal, vol. 8, no. 1, pp. 34-42, 2020.

[14] S. Shahzadi, M. Iqbal, U.Q. Zia, and T. Dagiuklas, "Infrastructure as a service (IaaS): A comparative performance analysis of open-source cloud platforms", in The 22nd IEEE International Workshop on Computer Aided Modeling and Design of Communication Links and Networks (CAMAD), Lund, Sweden, June 19-21, 2017, pp. 1-6.

[15] N. Kumar, Sh. Kumar Kushwaha, and A. Kumar, "Cloud computing services and its application", Advance in Electronic and Electric Engineering, vol. 4, no. 1, pp. 107-112, 2014.

[16] P. Bedi, B. Deep, P. Kumar, and P. Sarna, "Comparative study of OpenNebula, CloudStack, Eucalyptus and OpenStack", International Journal of Distributed and Cloud Computing, vol. 6, no. 1, pp. 3742, 2018.

[17] T. Rosado, and J. Bernardino, "Implementation of a low cost IaaS using Openstack", in Proceedings of the 11th International Joint Conference on Software Technologies (ICSOFT 2016), Lisbon, Portugal, July 24-26, 2016, vol. 1, pp. 298-303.

[18] S.-G. Topoloi, and E. Borcoci, "IaaS environment creation experiments with OpenStack", in The Eighteenth International Conference on Networks (ICN 2019), Valencia, Spain, 2019, pp. 37-43.

[19] OpenStack, Virtual machine image guide. Release Version: 15.0.0. June 18, 2017, 97 pp. 